\title{
Chiral cobalt complexes synthesised from I-valine: as potential catalysts for asymmetric henry reaction
}

\begin{abstract}
Chiral imines were synthesized from the amino acid L-Valine. The cobalt complexes of the chiral imines were found to catalyze asymmetric Henry reaction between nitromethane and benzaldehyde. The chiral nitro aldol was formed in excellent yield and ee. The possible mechanism for the asymmetric Henry reaction catalysed by chiral cobalt complexes was discussed.
\end{abstract}

Keywords: organic molecules, asymmetric chemical catalysts, henry reaction, chiral amino alcohols, chiral bisimidazolines, $\mathrm{x}$-ray, helical polymers, benzaldehydes, heterobimetallic catalyst, stereoselective synthesis, chiral $\alpha$-amino alcohols, l-valine ester hydrochloride, triethylamine, 1 -valine methylester, ${ }^{13} \mathrm{CNMR}$ spectrum; ${ }^{1} \mathrm{HNMR}$ spectrum, ir spectra, nitromethane
Volume I Issue 6 - 2017

\section{Pachiannan Sakthipriya, Sakshi Joseph, Nallamuthu Ananthi}

Department of Chemistry, Karunya University, India

Correspondence: Nallamuthu Ananthi, Department of Chemistry, Karunya University, Coimbatore- 64 I I I4, India, Tel 9994 I497 62, Email write2ananthi@gmail.com

Received: November 15, 2017| Published: December 06, 2017

\section{Introduction}

Chirality of organic molecules plays an enormous role in areas ranging from medicine to material science, yet the synthesis of such entities in one enantiomeric form is one of the most difficult challenges. Properties of molecules and molecular arrays depend on chirality. Molecular communication in biological systems emanates from this intrinsic structural feature. ${ }^{1-8}$ Despite this importance, the ability to obtain chiral molecules in enantiopure form remained extremely limited until recently.

Asymmetric chemical catalysts have the greatest potential for general asymmetric synthesis since virtually no constraints exist in terms of molecular design, except those imposed by the human designing them, or in terms of what reactions are potentially capable of being performed asymmetrically. Several developments accelerated the growth of defined transition metal complexes for asymmetric catalysis. First, the ability to synthesize and characterize well defined transition metal complexes improved dramatically. Second, access to defined complexes set the stage for understanding the implication of structure for function, which begot the development of defined transition metal complexes, typically hybrids of organic entities and transition metals, for chemical catalysis. Third, the ability for individuals to wed the understanding that arises by integrating theoretical, physical, organic, and inorganic chemistry with solving complex problems becomes enabling.

There are several reasons why L-Valine has become important in Asymmetric catalysis. L-Valine is an important useful chiral amino acid, which can be applied to catalyze many asymmetric reactions. It has been used over a wide range of organic synthesis reaction to obtain enantiomerically or diastereomerically enriched chiral products. L-Valine is nontoxic, inexpensive and readily available in both enantiomeric forms. It offers comfortable reaction conditions $\&$ recyclability. It is a useful ligand in asymmetric transition metal catalysis.

The Henry Reaction is a base-catalyzed C-C bond forming reaction between nitroalkanes and aldehydes or ketones. It is similar to aldol addition, and also referred as nitro aldol reaction. If acidic protons are available (i.e. when $\mathrm{R}=\mathrm{H}$ ), the products tend to eliminate water to give nitroalkenes. Therefore, small amount of base should be used if the isolation of the $\beta$-hydroxy nitro compounds is desired. There are various applications of chiral nitro aldol products (Scheme 1).

Many of these uses have been exemplified in the syntheses of various pharmaceuticals including the $\beta$-blocker (S)-propranolol ${ }^{9-12}$ as explained in scheme 1 , chiral nitro aldols are the starting material for many essential chiral products.

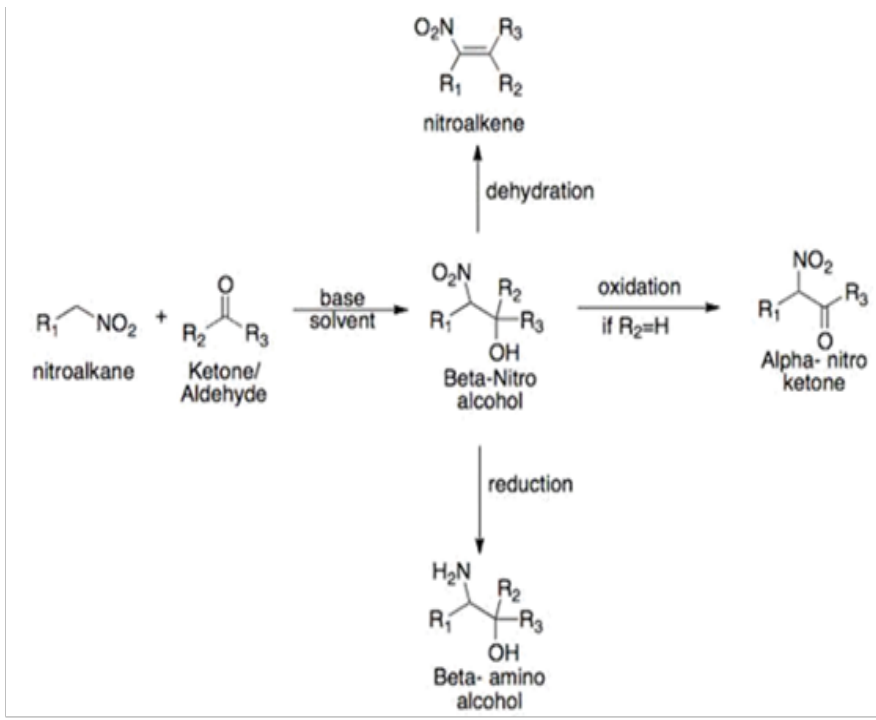

Scheme I Synthetic application of chiral nitro aldol.

Kuoyan et al. ${ }^{13}$ reported the rational design of sterically and electrically easily tunable chiral bis (imidazoline) ligands from chiral amino alcohols. A small library of chiral bisimidazolines has been constructed. The method has provided an easy and simplified route to a diverse set of air-stable and water-tolerant chiral bis (imidazoline) ligands. The dual Lewis Acid/Bronsted base catalytic system generated from the $\mathrm{Cu}(\mathrm{OTf})_{2}$ complex and $\mathrm{Et}_{3} \mathrm{~N}$ was able to catalyze asymmetric Henry reactions between aldehydes and nitromethane effectively at room temperature, and also to tolerate a wide scope of aldehydes 
with excellent enantiomeric excesses. Not only aromatic aldehydes but also aliphatic aldehydes afforded the nitroalcohol products, with enantiomeric excess in $93-98 \%$ range. This dual catalytic system is among the most effective systems so far reported for the asymmetric Henry reactions.

Daisuke et al. ${ }^{14}$ reported chiral tetraaminophosphonium salts possessing the phosphorus-centered [5.5]-spirocyclic core synthesized in a single step from $\mathrm{L}$-valine derived diamine. The three dimensional molecular structure was successfully verified by the single crystal $\mathrm{X}$-ray diffraction analysis, which also identified a secondary interaction between the phosphonium cation and chloride ion via double hydrogen bonding. The potential of this novel onium salt as a chiral organic catalyst has been demonstrated in an application to asymmetric direct Henry reaction.

Takayoshi et al ${ }^{15}$ reported a series of new binaphthyl-containing sulfonyldiamine ligands which were readily synthesized in two steps starting from commercially available chiral 1,2-diamines. The $(R, R)$ diamine-(R)-binaphthyl ligand- $\mathrm{CuCl}$ complex smoothly catalyzed the enantioselective Henry reaction with the assistance of pyridine to give the corresponding adduct with high enantiomeric excess (up to 93\%). Moreover, the system promotes the diastereoselective Henry reaction in $s y n$-selective manner to give the adduct in up to $99 \%$ yield with 92:8 syn/anti selectivity.

Bin Tan et al. ${ }^{16}$ synthesized a highly functionalized cyclopentanes with four stereogenic carbons including two quaternary stereo centers in excellent yields (90-95\%) with complete diastereoselectivities and excellent enantioselectivities $(88-96 \%$ ee) by the organ catalyzed asymmetric Domino Michael Henry reaction. In 2009 Hun Young et al. ${ }^{17}$ reported a new approach to enantio enriched Henry products by the use of metal ligand complexes generated from $\mathrm{Cu}(\mathrm{I})$ and $\mathrm{Zn}(\mathrm{II})$ metals with readily available chiral amino alcohol as catalysts.

Gonzalo et al. ${ }^{18}$ reported catalytic highly enantioselective Henry addition of methyl 4-nitrobutyrate to aldehydes using a $\mathrm{Cu}$ (II)-amino pyridine complex as catalyst. The products resulting from this reaction constitute a new, highly versatile family of chiral building blocks as a result of the presence of three different functional groups on the molecule. These products have been transformed into nonracemic chiral gamma lactams, 5-hydroxy-5-substituted levulinic acid derivatives, and delta-lactones. Yirong et al. ${ }^{19}$ reported a small library of C1-symmetric chiral diamines constructed via condensing exo-()-bornylamine or $(+)-(1 \mathrm{~S}, 2 \mathrm{~S}, 5 \mathrm{R})$-menthylamine with various cbzprotected amino acids. Among them, ligand $/ \mathrm{CuCl}_{2} \cdot 2 \mathrm{H}_{2} \mathrm{O}$ complex $(2.5 \mathrm{~mol} \%)$ showed outstanding catalytic efficiency for Henry reaction between a variety of aldehydes and nitroalkanes to afford the expected products in high yields (up to $98 \%$ ) with excellent enantioselectivities (up to 99\%) and moderate to good diastereoselectivities (up to 90:10).

Zhenglin et al. ${ }^{20}$ reported a series of novel helical poly phenylacetylenes bearing amino functionalized cinchona alkaloid pendant groups connecting to the phenyl rings through an amide linkage were prepared by the polymerization of the corresponding phenylacetylenes using a rhodium catalyst. All of the polymers formed a preferred handed helical conformation biased by the optically active pendants, resulting in the induced circular dichroism in their $\pi$ - conjugated polymer backbone regions.

The optically active helical polymers efficiently catalyzed the asymmetric Henry reaction of benzaldehydes with nitromethane, giving optically active products up to $94 \%$ enantiomeric excess (ee).
The enantioselectivity was remarkably higher than those catalyzed by the corresponding nonhelical poly (phenylacetylene) $(18 \% e e)$ and the monomer $(28 \% e e)$.

Tatsuya et al. ${ }^{21}$ reported full details of an anti-selective catalytic asymmetric nitroaldol reaction promoted by a heterobimetallic catalyst comprised of Nd-salt, an amide based ligand and NaHMDS (Sodium hexamethyldidilazide). A systematic synthesis and evaluation of amide based ligands led to the identification of optimum ligand, which provided a suitable platform for the $\mathrm{Nd} / \mathrm{Na}$ heterobimetallic complex.

William et al. $^{22}$ reported a highly stereoselective synthesis of conformationally constrained cyclic $\gamma$-amino acids. The key step involves an intramolecular cyclization of a nitronate onto a conjugated ester, promoted by a bifunctional thiourea catalyst. This methodology has been successfully applied to generate a variety of $\gamma$-amino acids, including some containing three contiguous stereocenters, with very high diastereoselectivity and excellent enantioselectivity. It is postulated that an interaction that is key to the success of the process is the simultaneous coordination of the thiourea functionality to both the conjugated ester and the nitronate. Finally, the synthetic utility of these compounds was demonstrated in the synthesis of two dipeptides derived from the $\mathrm{C}$ - and $\mathrm{N}$-termini.

Wei et al. ${ }^{23}$ reported a series of bis (sulfonamide)-diamine (BSDA) ligands from commercially available chiral $\alpha$-amino alcohols and diamines. The chiral BSDA ligand, coordinated with $\mathrm{Cu}(\mathrm{I})$, catalyzes the enantioselective Henry reaction with excellent enantioselectivity (up to $99 \%$ ). Moreover, with the assistance of pyridine, the system promotes the diastereoselective Henry reaction with various aldehyde substrates and gives the corresponding syn-selective adduct up to a $99 \%$ yield and $32.3: 1$ syn/anti selectivity. The enantiomeric excess of the syn adduct was $97 \%$. Magnus et al. ${ }^{24}$ reported a direct asymmetric organocatalytic aza-Henry reaction in which a new bifunctional Bronsted-acid-catalyzed activation of nitroalkanes provides an efficient access to $\alpha, \beta$-diamino acids with high dia- and enantioselectivities under mild and base free reaction conditions.

Hua et al. ${ }^{25}$ reported a series of new modular bifunctional chiral thiourea organocatalysts synthesized from natural cinchona alkaloids and amino acids, and their performance in the aza-Henry reaction of nitroalkanes to imines, in the Michael addition of acetylacetone to nitroolefins and in the Michael addition of acetone to nitroolefins. Under the mild conditions, the important building blocks $\beta$-nitro amines and $\gamma$-nitro carbonyl compounds could be obtained in good yields (up to 95\%) with excellent enantioselectivities (up to $99 \%$ ee) and diastereoselectivity (up to 17:1).

Qipu et al. ${ }^{26}$ reported a highly diastereoselective ( $\left.\mathrm{dr}>99: 1\right)$ and enantioselective (ee value up to $98 \%$ ) synthesis of a modified trisubstituted cyclohexanols achieved by using a tandem Henry Michael reaction between nitromethane and 7-oxo-hept-5-enals catalyzed by the Misaki-Sugimura guanidine.

Gonghao et al. ${ }^{27}$ reported a series of chiral amino alcohol ligands prepared using commercial amino alcohols and phthalaldehydes. These ligands were used as catalysts in asymmetric Henry reactions in the presence of $\mathrm{Cu}$ (II) ions giving good yields (up to 97\%) and enantiomeric excesses (ee, up to $98 \%$ ).

Recently Gabriela et al. ${ }^{28}$ reported a new series of 2-(pyridine-2yl) imidazolidine-4-thione derivatives. Their corresponding copper (II) complexes were found to be highly enantioselective catalysts for 
asymmetric Henry reactions (up to $98 \%$ ee). Immobilization of these complexes by anchoring onto Merrifield ${ }^{\mathrm{TM}}$ resin with respect to their use as recyclable catalysts was subsequently performed.

\section{Experimental section}

\section{General}

${ }^{1} \mathrm{H}(400 \mathrm{MHz})$ and ${ }^{13} \mathrm{CNMR}(100 \mathrm{MHz})$ spectra were recorded in $\mathrm{CDCl}_{3}$ with a BRUKER AMX-500MHz instrument using TMS as an internal standard. Commercial precoated silica gel (Merck 60F254) plates were used for TLC. 60-120 mesh silica gel was used for column chromatography. Enantiomeric excess was determined with a Shimadzu 2010A HPLC instrument (Chiral column: Chiralcel OD, Mobile phase: 98:2 hexane/i-PrOH, FLOW RATE: $0.5 \mathrm{ml} / \mathrm{min}$, UV detector $\lambda=254 \mathrm{~nm}$. FTIR spectra were recorded with a Perkin ElmerDXB spectrometer. Melting point was determined with a Kherea digital melting point apparatus and is uncorrected. All the chemicals were purchased from Merck. All the solvents used were purchased from Merck and used after purification.

\section{General procedure for synthesis of L-Valine ester hy- drochloride Ia-d}

L-Valine $(2 \mathrm{~g}, 17.1 \mathrm{mmol})$ was dissolved in $20 \mathrm{ml}$ of respective alcohols. To this thionyl chloride $(2 \mathrm{ml}, 17.1 \mathrm{mmol})$ was added drop wise under an ice cold condition. Then the reaction mixture was stirred overnight. Then the excess thionyl chloride was removed which results L-Valine esters $(2.8 \mathrm{~g})$ in quantitative yield (Scheme 2).

\section{General procedure for the synthesis of chiral imines} 2a-d

To an alcoholic solution of L-Valine ester hydrochloride, triethylamine was added to bring it to basic condition. Salicylaldehdye was added in a 1:1 molar ratio followed by anhydrous sodium sulphate and stirred at room temperature for 5 hours. Then the reaction mixture was filtered and the solvent was evaporated to yield a yellow crystalline imine with $90 \%$ yield (Scheme 3 ).
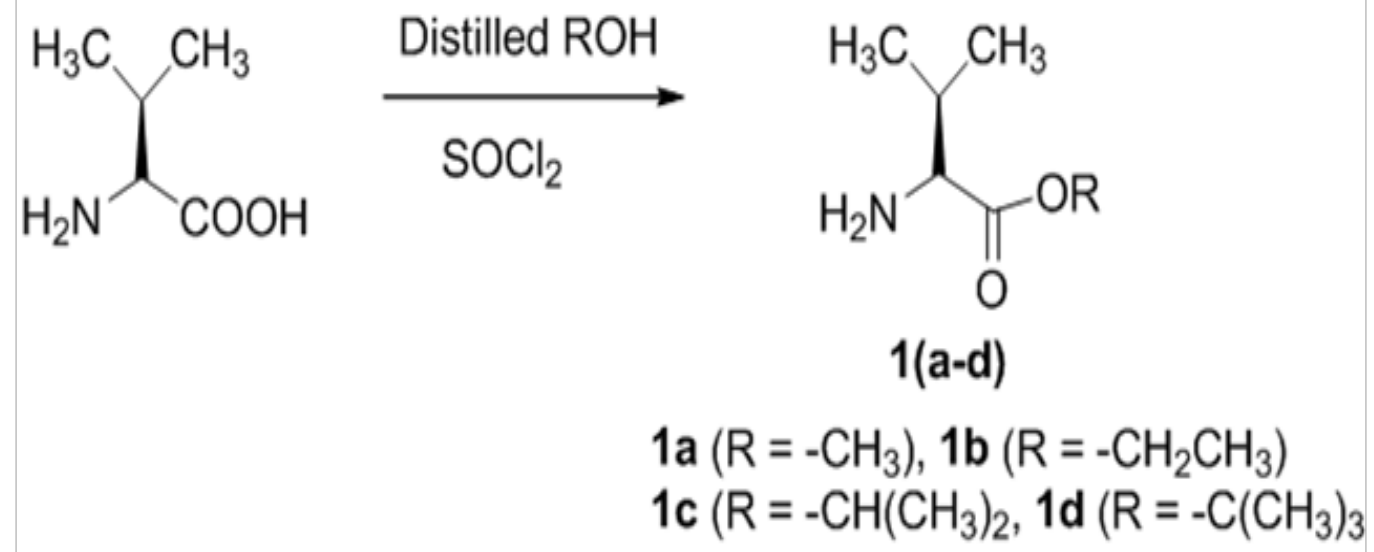

Scheme 2 Synthesis of L-Valine ester hydrochloride I(a-d).<smiles>CC(C)C(N)C(=O)O</smiles><smiles>O=Cc1ccccc1O</smiles><smiles>CCN(CC)[R16](=O)[Os]</smiles><smiles>[R]OC(=O)C(/N=C/c1ccccc1O)C(C)C</smiles>

Scheme 3 Synthesis of chiral imines 2a-d.

\section{General procedure for the synthesis of cobalt comple- xes 3a-d}

To an alcoholic solution of chiral imine, alcoholic solution of cobalt acetate was added in 1:1 molar ratio and stirred at room temperature for 4 hours. After the completion of the reaction monitored by TLC the solvent was evaporated using rotor evaporator to yield a dark green cobalt complex with $90 \%$ yield (Scheme 4).

\section{General procedure for catalytic asymmetric henry reaction}

To an ethanolic solution of chiral cobalt complex $3 \mathrm{a}(0.036 \mathrm{~g}$,
$0.1 \mathrm{mmol})$, nitromethane $(0.154 \mathrm{~g}, 1 \mathrm{mmol})$ was added followed by the addition of triethylamine $(0.01 \mathrm{ml}, 1 \mathrm{~mol} \%)$ (Scheme 5). Then benzaldehyde $(0.212 \mathrm{ml}, 1 \mathrm{mmol})$ was added drop wise and the reaction mixture was stirred for 24 hours at room temperature. After 24 hours, $1 \mathrm{M} \mathrm{HCl}$ was added to the reaction mixture, and the solvent was evaporated. The aqueous layer was extracted with ethyl acetate. The resulted organic layer was dried over anhydrous sodium sulphate. The product nitroaldol was purified by column chromatography using silica gel as an adsorbent and 95:5 hexane: ethylacetate as an eluant. $[\alpha]_{25}^{\mathrm{D}}=-13.9(\mathrm{c}=1$, Ethanol $)\left[\right.$ Lit. $\left.^{14 \mathrm{a}}[\alpha]_{20}^{\mathrm{D}}\right]$. 


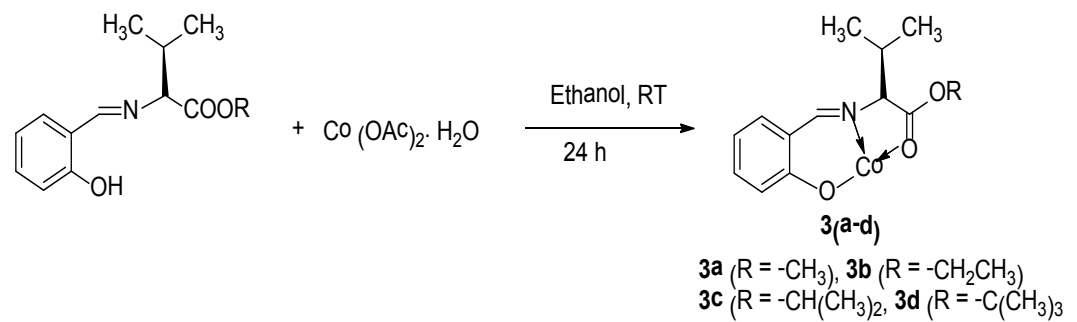

Scheme 4 Synthesis of chiral cobalt complexes 3(a-d).<smiles>C[N+](=O)[O-]</smiles>

Scheme 5 Asymmetric Henry reaction catalysed by 3a.

\section{Results and discussion}

The formation of ester was confirmed from the band present at $1744 \mathrm{~cm}^{-1}$ in FTIR spectrum. A sharp and intense singlet peak at $\delta=3.6 \mathrm{ppm}$ in the ${ }^{1} \mathrm{HNMR}$ spectrum also confirms the successful formation of L-Valine methylester. All the carbon atoms present in L-Valine methylester hydrochloride have their corresponding signals in the ${ }^{13} \mathrm{CNMR}$ spectrum. A peak at $\delta 170.66 \mathrm{ppm}$ was assigned to the ester carbonyl carbon present in L-Valine methylester hydrochloride. The carbon atom present in the methoxy group was found at $\delta 57.23 \mathrm{ppm}$ in the ${ }^{13} \mathrm{CNMR}$ spectrum. The product identity was further confirmed by comparing the literature value of $[\alpha]^{\mathrm{D}}$ and the melting 3a, $\mathrm{Et}_{3} \mathrm{~N}$, Ethanol

$24 \mathrm{~h}$

point. Spectral characterization data of other esters were given in Table 1, (Figure $1 \& 2$ ).

L-Valine methyl ester hydrochloride was condensed with salicylaldehdye to form the imine. The formation of product was confirmed from FTIR spectrum, a stretching frequency band at $1645 \mathrm{~cm}^{-1}$ corresponding to imine. ${ }^{1} \mathrm{HNMR}$ measurements by the singlet peak at $\delta 8.05 \mathrm{ppm}$ corresponding to imine. ${ }^{13} \mathrm{C}$ NMR of imine also confirms imine carbon in the compound at $135 \mathrm{ppm}$. The retention of configuration of the chiral source was monitored using the digital polarimeter. ${ }^{1} \mathrm{H}$ and ${ }^{13} \mathrm{CNMR}$ data of other imines were tabulated in Table 2 \& Figure 3.

Table I Spectral data of different L-Valine esters Ia-d

\begin{tabular}{|c|c|c|c|}
\hline cc & 'H NMR ( $\delta \mathrm{ppm})$ & ${ }^{13}$ C NMR ( $\delta$ ppm) & {$[\alpha]_{35}^{589}$} \\
\hline $\mathrm{la}$ & $8.4(\mathrm{~s}, 2 \mathrm{H}), 3.7-3.73(\mathrm{~d}, \mathrm{IH}), 2.5(\mathrm{~s}, 3 \mathrm{H}), 2 . \mathrm{I}-2,2(\mathrm{~s}, \mathrm{IH}), 0.9(\mathrm{~m}, 6 \mathrm{H})$ & $17.68,18.28,28.97,57.23,170.06$ & +41 \\
\hline $\mathrm{Ib}$ & $0.9 \mathrm{I}(6 \mathrm{H}, \mathrm{d}), \mathrm{I} .18(3 \mathrm{H}, \mathrm{t}), 2.7(\mathrm{IH}, \mathrm{m}), 4.2(2 \mathrm{H}, \mathrm{q}), 4.3(\mathrm{IH}, \mathrm{d})$ & $14.7,18.9,29.5,59.4,61.8,173$ & +18.7 \\
\hline Ic & $0.85(\mathrm{~d}, 6 \mathrm{H}), \mathrm{I} .32(\mathrm{~d}, 6 \mathrm{H}), 2,54(\mathrm{~m}, \mathrm{IH}), 4.2(\mathrm{~d}, \mathrm{IH}), 4.8(\mathrm{~m}, \mathrm{IH})$ & $18.9,22.5,29.4,60.03,71.24,173.4$ & +12.4 \\
\hline Id & $0.9 \mathrm{I}(6 \mathrm{H}, \mathrm{d}), \mathrm{I} .34(\mathrm{~s}, 9 \mathrm{H}), 2.6(\mathrm{IH}, \mathrm{m}), 4 . \mathrm{I}(\mathrm{IH}, \mathrm{d})$ & 18.7, 28.29, 29.54, 59.97, 82.02, I 72.3 & +41.8 \\
\hline
\end{tabular}

Table $2{ }^{\prime} \mathrm{H} \&{ }^{13} \mathrm{C}$ NMR data of chiral imines $2 \mathrm{a}-\mathrm{d}$

\begin{tabular}{|c|c|c|c|c|}
\hline Compound & 'H NMR ( $\delta$ ppm) & ${ }^{13} \mathrm{C}$ NMR ( $\left.\delta \mathrm{ppm}\right)$ & $\begin{array}{l}\text { Mass } \\
\text { spectral data } \\
\text { (EI) }\end{array}$ & {$[\alpha]_{35}^{589}$} \\
\hline $2 \mathrm{a}$ & $\begin{array}{l}\mathrm{I} .0 \mathrm{I}(6 \mathrm{H}, \mathrm{d}), 2.2 \mathrm{I}(\mathrm{IH}, \mathrm{m}), 3.05(\mathrm{IH}, \mathrm{d}), 3.5 \\
(\mathrm{IH}, \mathrm{s}), 3.77(3 \mathrm{H}, \mathrm{s}), 3.95(2 \mathrm{H}, \mathrm{dd}), 6.76-7.07(4 \mathrm{H}, \\
\text { Ar-H) }\end{array}$ & 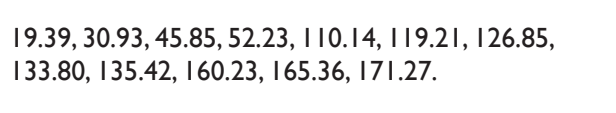 & $\begin{array}{l}235,212,185 \\
158\end{array}$ & +31.9 \\
\hline $2 b$ & $\begin{array}{l}\mathrm{I} .05(6 \mathrm{H}, \mathrm{d}), \mathrm{I} .37(3 \mathrm{H}, \mathrm{t}), 2.22(\mathrm{IH}, \mathrm{m}), 3.06 \\
(\mathrm{IH}, \mathrm{d}), 3.93(\mathrm{dd}, 2 \mathrm{H}), 4.17(2 \mathrm{H}, \mathrm{q}), 6.85-7.0 \mathrm{I} \\
(3 \mathrm{H}, \mathrm{Ar}-\mathrm{H})\end{array}$ & 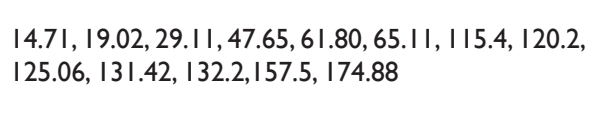 & $\begin{array}{l}249,220,199 \\
172\end{array}$ & +8.2 \\
\hline $2 c$ & $\begin{array}{l}\mathrm{I} .03(6 \mathrm{H}, \mathrm{dd}), \mathrm{I} .40(6 \mathrm{H}, \mathrm{d}), 2.3 \mathrm{I}(\mathrm{IH}, \mathrm{m}), 3.09 \\
(\mathrm{IH}, \mathrm{d}), 3.93(2 \mathrm{H}, \mathrm{dd}), 4.8(\mathrm{IH}, \mathrm{m}), 6.8-7.03(3 \mathrm{H}, \\
\mathrm{Ar}-\mathrm{H})\end{array}$ & 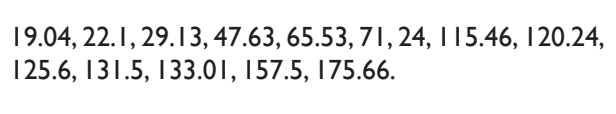 & $\begin{array}{l}263,205,213 \\
186\end{array}$ & +17.3 \\
\hline $2 d$ & $\begin{array}{l}\mathrm{I} .05(6 \mathrm{H}, \mathrm{dd}), \mathrm{I} .46(9 \mathrm{H}, \mathrm{s}), 2.26(\mathrm{IH}, \mathrm{m}), 3.09(\mathrm{IH}, \mathrm{d}) \text {, } \\
3.93(\mathrm{~d}, 2 \mathrm{H}), 6.85-7.0 \mathrm{I}(3 \mathrm{H}, \mathrm{Ar}-\mathrm{H})\end{array}$ & 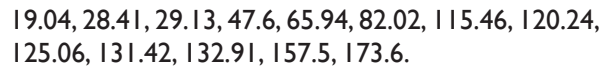 & $\begin{array}{l}277,213,227 \\
199\end{array}$ & +14.3 \\
\hline
\end{tabular}




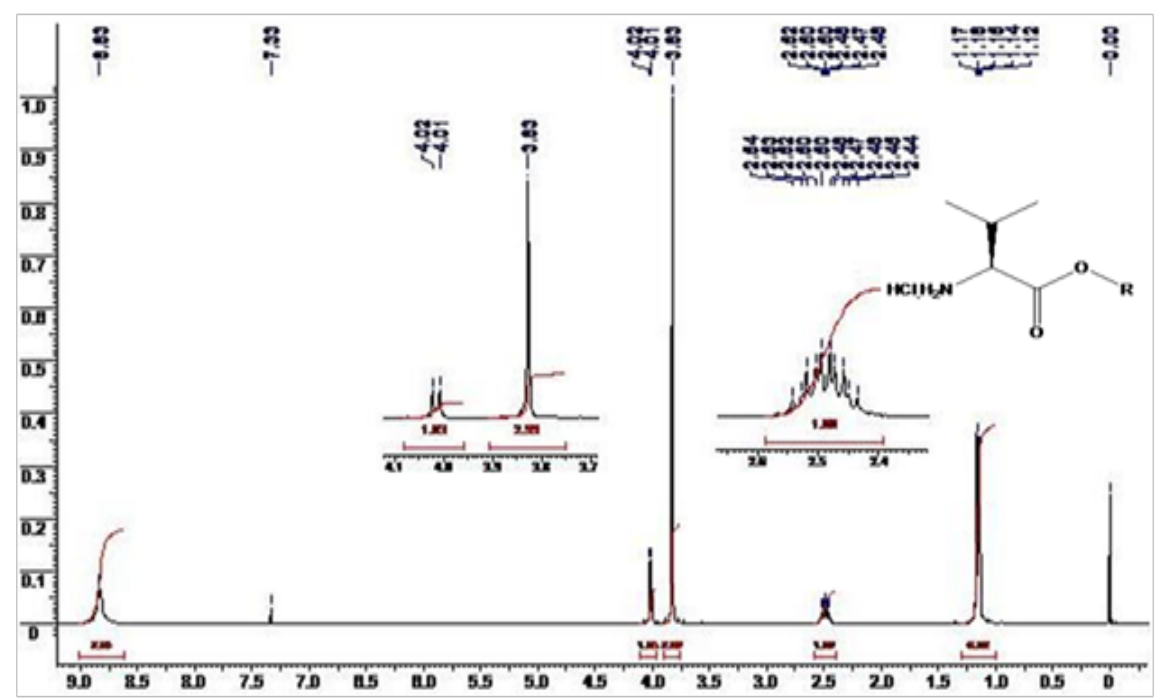

Figure I 'H NMR spectrum of L-Valine methylester hydrochloride la.

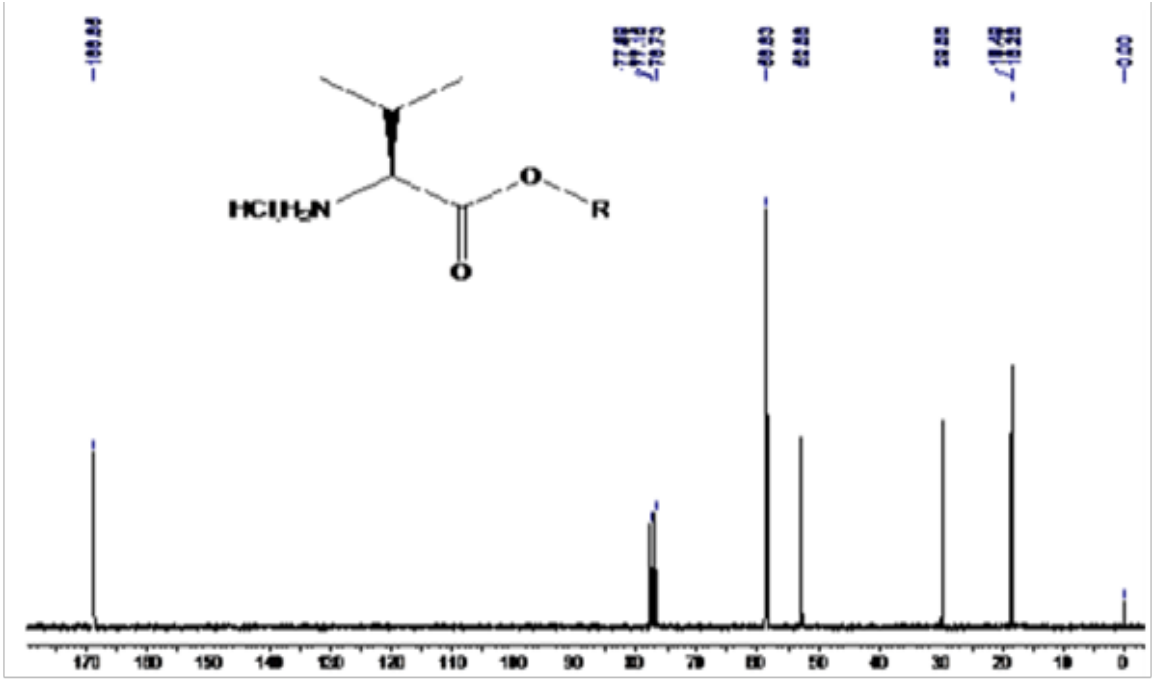

Figure $2{ }^{13} \mathrm{C}$ NMR spectrum of L-Valine methylester hydrochloride la.

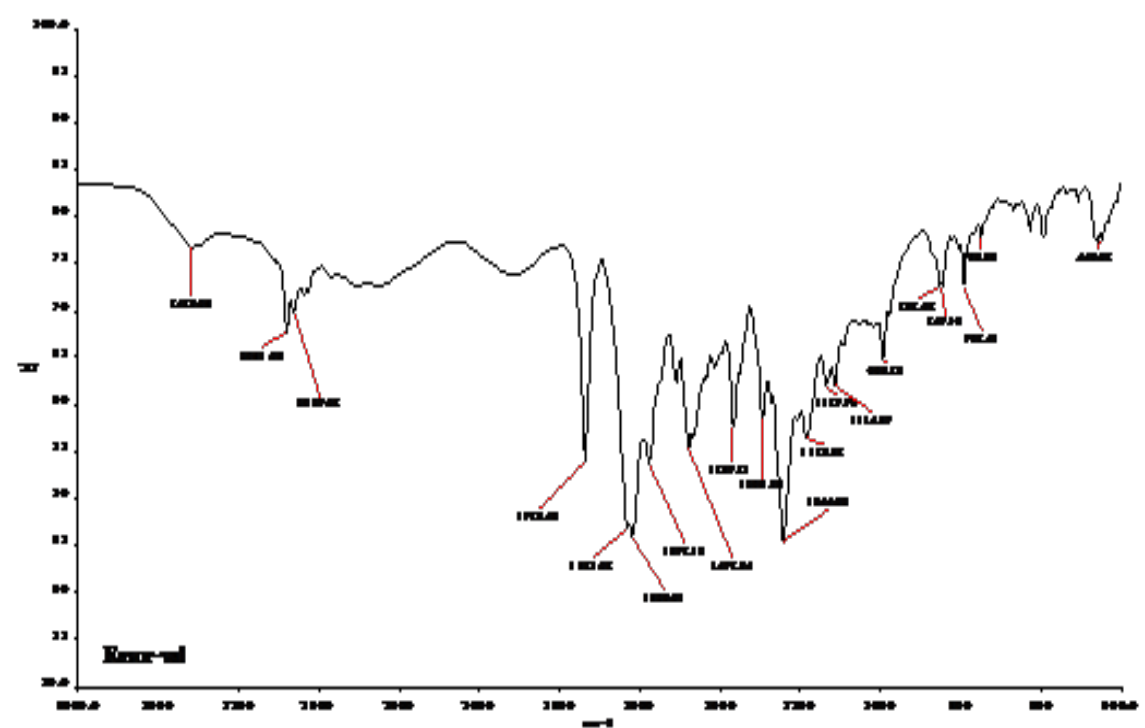

Figure 3 FTIR spectrum (R,E)-methyl 2-(2-hydroxybenzylideneamino)- 3-methyl butanoate 2a. 
The IR spectra of the metal complexes and the corresponding ligands show significant changes in the IR frequencies. Shift of some of the characteristic vibrational frequencies of the ligand upon complexation with metals provides evidence of the mode of binding of the ligand to the cobalt ion. The IR spectrum of the chiral ligands (1a-d) exhibits a broad band in the range $3408-3440 \mathrm{~cm}^{-1}$ which is assigned to the phenolic - $\mathrm{OH}$ group. The disappearance of this band clearly shows the ligand coordination around the metal ion through phenolic oxygen atom. This causes $\gamma(\mathrm{C}-\mathrm{O})$ to shift to lower frequencies from that of the free ligand, which is due to the weaker $\mathrm{C}-\mathrm{O}$ stretching upon coordination with the cobalt metal ion. The IR frequency of azomethine group $\gamma(\mathrm{C}=\mathrm{N})$ shifts to lower wave numbers by $20-30 \mathrm{~cm}^{-1}$ upon coordination. This shift of IR frequency confirms the coordination of ligand with metal through imine nitrogen atom. The IR frequency shifts of other chiral cobalt complexes are given in Table 3 \& (Figure 4).

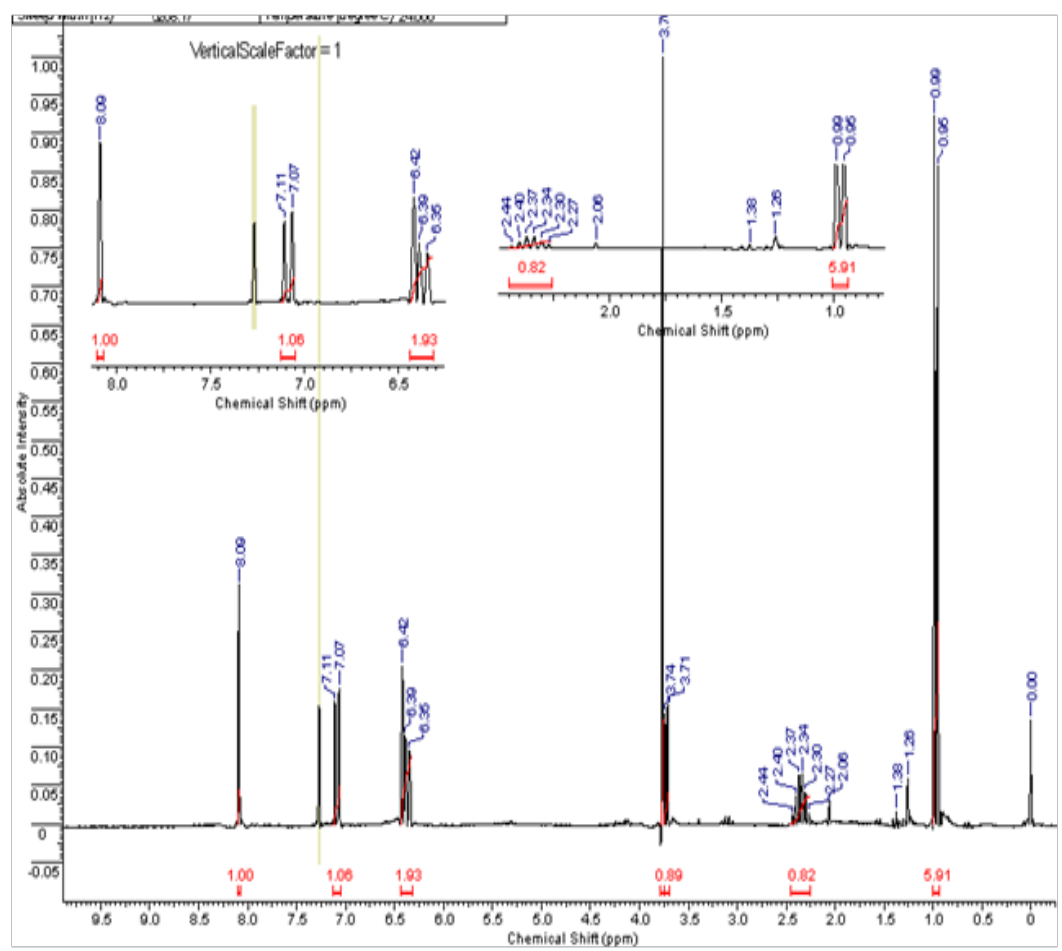

Figure 4 'H-NMR spectrum of (R, E)-methyl 2-(2-hydroxybenzylideneamino)- 3-methyl butanoate 2a.

Table 3 FTIR spectral data of chiral imines and their cobalt complexes

\begin{tabular}{|c|c|c|}
\hline $\begin{array}{l}\text { S. } \\
\text { No }\end{array}$ & Chiral imines 2a-d & Cobalt complexes $3 \mathrm{a}-\mathrm{d}$ \\
\hline I & $\begin{array}{l}\text { 2a: I730 (C=O), I } 645 \\
(\mathrm{C}=\mathrm{N}), 30 \mathrm{I} 0(\mathrm{O}-\mathrm{H}) \\
\text { I453(C-N) }\end{array}$ & $\begin{array}{l}\text { 3a: I } 726(\mathrm{C}=\mathrm{O}), 1615(\mathrm{C}=\mathrm{N}) \text {, } \\
3010(\mathrm{O}-\mathrm{H}), 1443(\mathrm{C}-\mathrm{N})\end{array}$ \\
\hline 2 & $\begin{array}{l}\text { 2b: I } 727(C=O), I 642 \\
(C=N), 3030(\mathrm{O}-\mathrm{H}), \\
\text { I449(C-N) }\end{array}$ & $\begin{array}{l}\text { 3b: I } 726(\mathrm{C}=\mathrm{O}), \mathrm{I} 617(\mathrm{C}=\mathrm{N}) \text {, } \\
3028(\mathrm{O}-\mathrm{H}), \mathrm{I} 443(\mathrm{C}-\mathrm{N})\end{array}$ \\
\hline 3 & $\begin{array}{l}\text { 2c: I739 (C=O), I640 } \\
(\mathrm{C}=\mathrm{N}), 3030(\mathrm{O}-\mathrm{H}), \\
\text { I446(C-N) }\end{array}$ & $\begin{array}{l}3 c: 1730(C=O), 16 I 5 \\
(C=N), 3030(O-H), 1443 \\
(C-N)\end{array}$ \\
\hline 4 & $\begin{array}{l}2 \mathrm{~d}: 1739(\mathrm{C}=\mathrm{O}), 1646 \\
(\mathrm{C}=\mathrm{N}), 3030(\mathrm{O}-\mathrm{H}), \\
\text { I446(C-N) }\end{array}$ & $\begin{array}{l}\text { 3d: I } 726(\mathrm{C}=\mathrm{O}), \mathrm{I} 605(\mathrm{C}=\mathrm{N}) \text {, } \\
3025(\mathrm{O}-\mathrm{H}), \mathrm{I} 44 \mathrm{I}(\mathrm{C}-\mathrm{N})\end{array}$ \\
\hline
\end{tabular}

Asymmetric Henry reaction was planned to carry out between benzaldehyde and nitromethane using chiral cobalt complexes 3a-d as catalysts. Initially the optimization of reaction conditions for asymmetric Henry reaction was carried out using chiral complex 3a (Scheme 5). The effect of the structure of chiral cobalt complexes $3(a-d)$ on the catalytic activity in the asymmetric Henry reaction was checked by employing the ligands $3(\mathrm{a}-\mathrm{d})$ as catalysts in. The results of the reactions are given in Table 5 , (Figure $5 \& 6$ ).
Table 4 Optimization of reaction conditions for asymmetric Henry reaction using chiral cobalt complex $3 \mathrm{a}$ as catalyst

\begin{tabular}{|c|c|c|c|c|}
\hline $\begin{array}{l}\text { S. } \\
\text { no. }\end{array}$ & $\begin{array}{l}\text { Amount } \\
\text { of catalyst } \\
\text { (mol \%) }\end{array}$ & $\begin{array}{l}\text { Temperature } \\
\left({ }^{\circ} \mathrm{C}\right)\end{array}$ & Yield (\%) & ee $(\%)^{b}$ \\
\hline I & 5 & 0 & 60 & 40 \\
\hline 2 & 5 & RT & 60 & 65 \\
\hline 3 & 5 & 40 & 90 & 0 \\
\hline 4 & 10 & 0 & 60 & 80 \\
\hline 5 & 10 & RT & 90 & 90 \\
\hline 6 & 15 & RT & 90 & 90 \\
\hline 7 & Stoichiometry & RT & 90 & 90 \\
\hline
\end{tabular}

aDetermined after isolation from column chromatography. ${ }^{b}$ Determined using chiral HPLC with chiralcel OD column. 
All cobalt complexes 3(a-d) catalysed asymmetric Henry reaction between benzaldehyde and nitromethane efficiently and gave the chiral nitro aldols in excellent yield and ee. A possible mechanism for the successful formation of chiral nitroaldols through asymmetric Henry reaction catalysed by chiral cobalt complexes can be proposed (Scheme 6). Nitronate anion of nitromethane with cobalt takes place leading to the formation of $\mathrm{b}$. Then aldehyde may be added which forms a six membered transition state $\mathrm{c}$. The attack of the nucleophilic $-\mathrm{CH}_{2} \mathrm{NO}_{2}$ group on electron deficient carbonyl group of the aldehyde takes place in the transition state $\mathrm{c}$. The product (R)-(-)-2-nitro-1phenylethanol (d) was formed after work up (Figure 7).

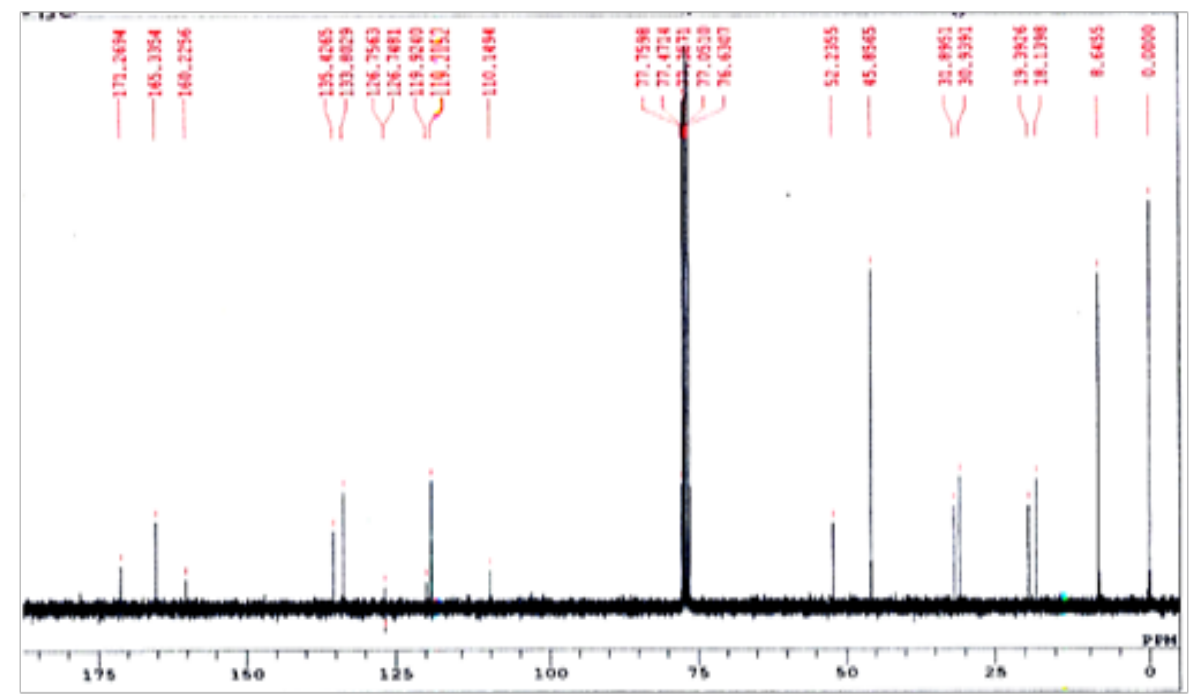

Figure $5{ }^{13} \mathrm{C}-\mathrm{NMR}$ spectrum of (R, E)-methyl 2-(2-hydroxybenzylideneamino)-3-methyl butanoate 2a.

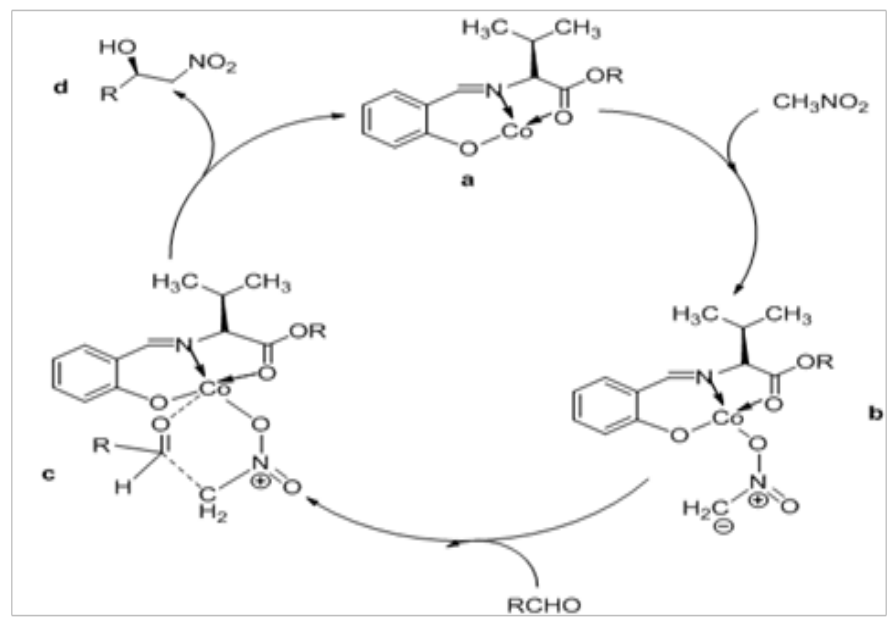

Scheme 6 Possible mechanism for asymmetric Henry reaction catalysed by chiral catalyst 3a.

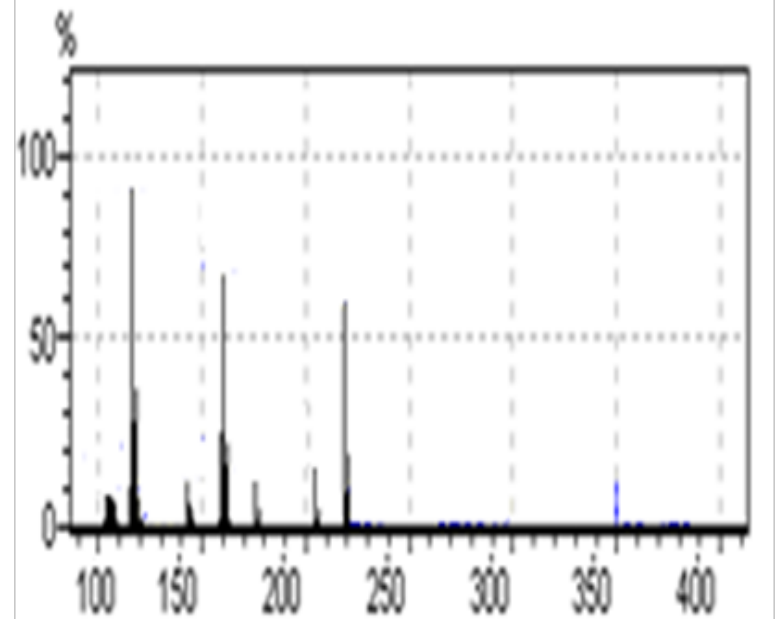

Figure 6 Mass spectrum of (R, E)-methyl 2-(2-hydroxybenzylideneamino)3-methyl butanoate $2 \mathrm{a}$.

Table 5 Asymmetric Henry reaction catalyzed by chiral porphyrin ligands $3(a-d)$

\begin{tabular}{llll}
\hline S. No. & Chiral cobalt complex & Yield (\%) $^{\mathrm{a}}$ & ee (\%) \\
\hline 1 & $3 \mathrm{a}$ & 90 & 90 \\
2 & $3 \mathrm{~b}$ & 90 & 90 \\
3 & $3 \mathrm{c}$ & 90 & 88 \\
4 & $3 \mathrm{~d}$ & 90 & 85 \\
\hline
\end{tabular}




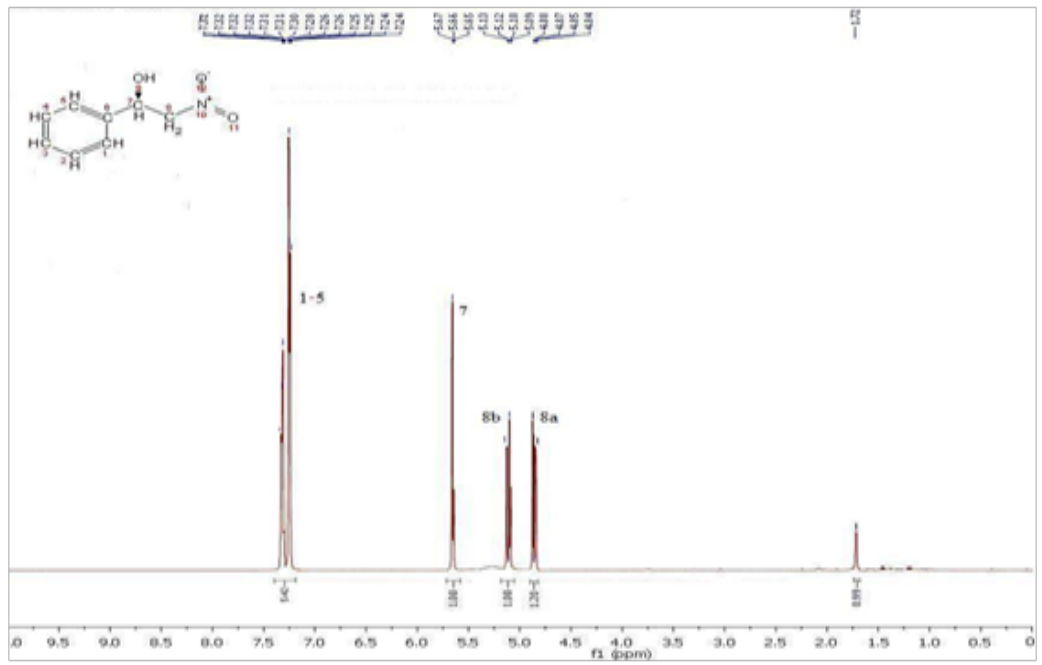

Figure 7 'H NMR spectrum of (R)-(-)-2-nitro- I-phenylethanol.

\section{Conclusion}

New chiral cobalt complexes were found to catalyze asymmetric Henry reaction between nitromethane and benzaldehyde. The chiral nitro aldol was formed in excellent yield and ee. The possible mechanism for the asymmetric Henry reaction catalysed by chiral cobalt complexes was discussed.

\section{Acknowledgements}

None.

\section{Conflict of interest}

The author declares no conflict of interest.

\section{References}

1. Van't Hoff JH. Formulas and structure in space. Bull Soc Chim. $1875 ; 23: 295-301$

2. Le Bel JA. On the relations between the atomic formulas of organic bodies and the rotatory power of their dissolutions. Bull Soc Chim France. $1874 ; 22: 337-347$

3. Natta G. Asymmetric synthesis of optically active di-isotactic polymers from cyclic monomers. Makromol Chem. 1961;43:68-75.

4. Natta G, Porri L, Valenti S. Synthesis of optically active cis-1, 4 poly(1,3-pentadiene) by asymmetric induction. Makromol Chem. 1963;67(1):225-228.

5. Coates GW, Waymouth RM. Enantioselective cyclopolymerization of 1,5-hexadiene catalyzed by chiral zirconocenes:a novel strategy for the synthesis of optically active polymers with chirality in the main chain. $J$ Am Chem Soc. 1993;115(1):91-98.

6. Natta G. Some remarks on the mechanism of the stereospecific ionic coordinated polymerization of hydrocarbon monomers. Pure Appl Chem. 1966;12(1-4):165-182.

7. Natta G. Macromolecular Chemistry. Science. 1965;147(3655):261-272.

8. Brintzinger HH, Fischer D, Muelhaupt R, et al. Stereospecific Olefin Polymerization with Chiral Metallocene Catalysts ${ }^{\dagger}$. Angew Chem Int Ed Engl. 1995;34(11):1143-1170

9. Biot JB. Bull Soc Philomath Paris. 1815:190.

10. Biot JB. Bull Soc Philomath Paris. 1816:125.
11. Richardson GM. Foundation of Stereochemistry. USA: Am Book Co; 1901.

12. Kekule A. Annals. 1858;106:154

13. Kuoyan M, Jingsong YP. Rational Design of Sterically and Electronically Easily Tunable Chiral Bisimidazolines and Their Applications in Dual Lewis Acid/Brønsted Base Catalysis for Highly Enantioselective Nitroaldol (Henry) Reactions. Chemistry-A European Journal. 2006;13(6):1863-1871.

14. Uraguchi D, Sakaki S, Ooi T. Chiral tetraaminophosphonium salt-mediated asymmetric direct Henry reaction. J Am Chem Soc. 2007;129(41):12392-12393.

15. Takayoshi A, Ryuta K, Yoko E, et al. Asymmetric Syn-Selective Henry Reaction Catalyzed by the Sulfonyldiamine-CuCl-Pyridine System. $J$ Org Chem. 2008;73(13):4903-4906.

16. Bin T, Pei JC, Xiaofei Z, et al. A Highly Diastereo- and Enantioselective Synthesis of Multisubstituted Cyclopentanes with Four Chiral Carbons by the Organocatalytic Domino Michael-Henry Reaction. Org Lett. 2008;10(16):3489-3492.

17. Kim HY, Oh K. Brucine--Derived Amino Alcohol Catalyzed Asymmetric Henry Reaction: An Orthogonal Enantioselectivity Approach. Org Lett. 2009;11(24):5682-5685.

18. Gonzalo B, Victor HO, Jose RP. Enantioselective Henry Addition of Methyl 4-Nitrobutyrate to Aldehydes. Chiral Building Blocks for 2-Pyrrolidinones and Other Derivatives. Org Lett. 2010;12(13):3058-3061.

19. Zhou Y, Dong J, Zhang F, et al. Synthesis of C1-symmetric chiral secondary diamines and their applications in the asymmetric copper(II)-catalyzed Henry (nitroaldol) reactions. J Org Chem. 2011;76(2):588-600.

20. Zhenglin T, Hiroki I, Hai YH, et al. Remarkable Enhancement of the Enantioselectivity of an Organocatalyzed Asymmetric Henry Reaction Assisted by Helical Poly(phenylacetylene)s Bearing Cinchona Alkaloid Pendants via an Amide Linkage. Macro Lett. 2012;1(2):261-265.

21. Nitabaru T, Nojiri A, Kobayashi M, et al. Anti-Selective Catalytic Asymmetric Nitroaldol Reaction via a Heterobimetallic Heterogeneous Catalyst. J Am Chem Soc. 2009;131(38):13860-13869.

22. Nodes WJ, Nutt DR, Chippindale AM, et al. Enantioselective Intramolecular Michael Addition of Nitronates onto Conjugated Esters: Access to Cyclic $\gamma$-Amino Acids with up to Three Stereocenters. J Am Chem Soc. 2009;131(44):16016-16017. 
23. Wei J, Xincheng L, Boshun W. A Highly Diastereo- and Enantioselective Copper (I)-Catalyzed Henry Reaction Using a Bis(sulfonamide)Diamine Ligand. J Org Chem. 2011;76(2):484-491.

24. Rueping M, Antonchick AP. Brønsted-Acid-Catalyzed Activation of Nitroalkanes: A Direct Enantioselective Aza-Henry Reaction. Org Lett. 2008;10(9):1731-1734.

25. Hua L, Xu Z, Xin S, et al. Modular Bifunctional Chiral Thioureas as Versatile Organocatalysts for Highly Enantioselective Aza-Henry Reaction and Michael Addition. Advanced Synthesis \& Catalysis. 2012;354(1112):2064-2274.
26. Qipu D, Huicai H, John Cong GZ. Highly Stereoselective Synthesis of Trisubstituted Cyclohexanols Using a Guanidine-Catalyzed Tandem Henry-Michael Reaction. J Org Chem. 2013;78(8):4153-4157.

27. Gonghao L, Fei Z, Lei W, et al. Asymmetric Henry reaction catalyzed by $\mathrm{Cu}(\mathrm{II})$-based chiral amino alcohol complexes with $\mathrm{C} 2$-symmetry. Tetrahedron: Asymmetry. 2016;27(16):732-739.

28. Gabriela N, Pavel D, Jan S, et al. Copper(II) complexes of 2-(pyridine-2-yl)imidazolidine-4-thione derivatives for asymmetric Henry reactions. Tetrahderon: Asymmetry. 2017;28(6):791-796. 